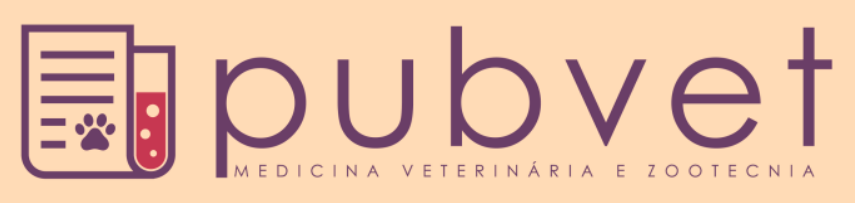

https://doi.org/10.22256/pubvet.v12n5a95.1-14

\title{
Gasto energético de bovinos em regime de pastejo: Métodos experimentais e fatores determinantes
}

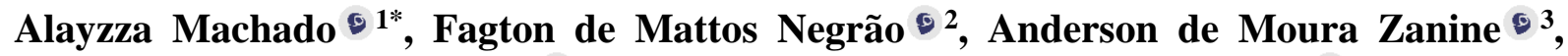 \\ Bruno Rafael Santos Borges ${ }^{01}$, Túlio Otávio Jardim D’Almeida Lins ${ }^{\bullet}$, Abílio da \\ Paixão Ciríaco ${ }^{2}$
}

\author{
${ }^{1}$ Discente do curso de Engenharia Agronômica, Instituto Federal de Rondônia, Colorado do Oeste-RO, Brasil. *E-mail: brunoborges0615@gmail.com \\ ${ }^{2}$ Departmento de Zootecnia, Instituto Federal de Rondônia, Colorado do Oeste-RO, Brasil. E-mail: fagton.negrao@ifro.edu.br, \\ tulio.jardim@ifro.edu.br, abilio.ciriaco@ifro.edu.br \\ ${ }^{3}$ Departmento de Zootecnia, Universidade Federal do Maranhão, Chapadinha-MA, Brasil. E-mail: anderson.zanine@ibest.com.br \\ *Autor para correspondência, Email: alayzzamachado@gmail.com
}

RESUMO. Em se tratando da bovinocultura brasileira, o sistema de criação predominante na maioria do país é o sistema de criação a pasto, caracterizado pelas vastas extensões de terras disponíveis e clima tropical que favorece o crescimento de gramíneas adaptadas. Uma característica notável desse sistema de criação é a sazonalidade na produção de forragem que é abundante no período chuvoso e escassa no período seco; tal situação compromete o desempenho dos índices zootécnicos dos animais e acarreta perdas na produtividade dos mesmos. Na cadeia produtiva animal, a energia é um fator de destaque na produção, sendo essencial para sustentar todos os processos vitais e metabólicos do corpo, entre outras funções. É necessário observar que animais criados a pasto possuem maior gasto energético, pois se movimentam mais em busca de alimento. Assim, objetivou-se elencar os métodos de determinação de gasto energético e demonstrar a importância da adoção de um manejo alimentar adequado.

Palavras chave: energia, metabolismo energético, nutrição animal

\section{Energy expenditure of grazing cattle: Experimental methods and determinants}

ABSTRACT. In the case of Brazilian cattle breeding, the principal breeding system in most of the country is the grazing system, characterized by vast tracts of land available and a tropical climate that favors the growth of adapted grasses. A notable feature of this breeding system is the seasonality of forage production that is abundant in the rainy season and scarce in the dry season; this situation compromises the performance of the performance indexes of the animals and causes losses in their productivity. In the animal production chain, energy is a prominent factor in production, being essential to sustain all vital and metabolic processes of the body, among other functions. It is necessary to observe that animals raised in pasture have greater energy expenditure, since they move more in search of food. Thus, the objective was to list methods of energy expenditure determination and to demonstrate the importance of adopting an adequate food management.

Key words: energy, energy metabolism, animal nutrition

\section{Gasto energético de bovinos en régimen de pastoreo: Métodos experimentales y factores determinantes}


RESUMEN. En lo que se refiere a la ganadería brasileña, el sistema de cría predominante en la mayoría del país es el sistema de producción a pasto, caracterizado por las amplias extensiones de tierras disponibles y clima tropical que favorece el crecimiento de las gramíneas adaptadas. Una característica notable de este sistema de cría es la estacionalidad en la producción de forraje que es abundante en el período lluvioso y escaso en el período seco; tal situación compromete el desempeño de los índices zootécnicos de los animales y acarrea pérdidas en la productividad de los mismos. En la cadena productiva animal, la energía es un factor destacado en la producción, siendo esencial para sostener todos los procesos vitales y metabólicos del cuerpo, entre otras funciones. Es necesario observar que animales criados a pasto poseen mayor gasto energético, pues se mueven más en busca de alimento. Así, se objetivó relacionar los métodos de determinación de gasto energético y demostrar la importancia de la adopción de un manejo alimentario adecuado.

Palabras clave: energía, metabolismo energético, nutrición animal

\section{Introdução}

A maioria dos bovinos brasileiros $(95 \%)$ é criada em condições extensivas de manejo, alimentando-se basicamente de capins tropicais, em especial do gênero Brachiaria, suplementados ou não com sal mineralizado ou sal proteinado (Ferraz \& Felício 2010). Cerca de $75 \%$ do crescimento dos capins tropicais ocorre no período chuvoso, quando as concentrações de energia, proteína e fósforo estão altas. Sem suplementação adequada no período seco, ocorre o surgimento de deficiências destes nutrientes que provocam queda de produtividade e prejuízos econômicos (Prado 2010; $\underline{\text { Berchielli }}$ et al. 2011).

Diferentemente da produção em confinamento, bovinos criados a pasto gastam grande parte do dia caminhando e colhendo forragem, apresentando assim, um gasto extra de energia. A atividade de pastejar pode aumentar os requerimentos de energia de bovinos criados a pasto em comparação aos confinados (Moraes et al. 2009). A energia é considerada fator limitante à vida e às funções produtivas e, portanto, sua determinação nos alimentos é de extrema importância para o perfeito atendimento das necessidades nutricionais (Cabral et al. 2006).

Atualmente, os sistemas empresariais adotados na produção de bovinos têm como objetivo o aumento da produtividade e a da rentabilidade econômica do setor. Nesse sentido, o manejo alimentar é um dos principais fatores responsáveis pela baixa eficiência produtiva e qualitativa da pecuária brasileira, e é por isso que se tem buscado com tanto afinco soluções para melhorar a qualidade nutricional dos rebanhos. Logo, o conhecimento da composição bromatológica dos alimentos disponíveis no Brasil e das exigências nutricionais dos animais, possibilita a adoção de medidas de manejo que resultem em maior eficiência alimentar e, conseqüentemente, econômica (Valadares Filho et al. 2016).

Considerando a premissa, objetivou-se, por meio desta revisão, abordar diferentes métodos de determinação do gasto energético de bovinos em regime de pastejo.

\subsection{Energia}

A energia não é considerada nutriente; ela é liberada do alimento uma vez que os constituintes orgânicos (carboidratos, proteínas e lipídeos) são susceptíveis à oxidação. A energia é definida como o potencial para realizar trabalho. É limitante no desempenho dos ruminantes, e merece especial atenção dos nutricionistas no que diz respeito às exigências do animal e à disponibilidade nos alimentos (Berchielli et al. 2011). Ela pode ser mensurada durante sua transformação de uma forma para outra e pode ser expressa em diversas unidades, sendo o Joule (J) e a caloria (cal), as unidades preferenciais para quantificar a energia (NRC 2000), como é demonstrado no Quadro 1.

Quadro 1. Principais unidades de energia

\begin{tabular}{|lc|}
\hline Unidade & Conversão \\
\hline $1 \mathrm{~J}$ & $0,239 \mathrm{cal}$ \\
1 cal & $4,184 \mathrm{~J}$ \\
1 quilocaloria (Kcal) & $1000 \mathrm{cal}$ \\
1 Kcal & $4,184 \mathrm{KJ}$ \\
1 Megacaloria (Mcal) & $1000 \mathrm{Kcal}$ \\
1 Mcal & $4,184 \mathrm{MJ}$ \\
$1 \mathrm{~g}$ NDT & $4,409 \mathrm{Kcal}$ \\
\hline
\end{tabular}

Fonte: Adaptado de Lawrence et al. (2012). 
A energia é liberada do alimento após complexo processo de metabolismo, sendo que os constituintes orgânicos de dietas são sensíveis à oxidação. Algumas moléculas não são oxidadas, mas são imediatamente reconstituídas em novas estruturas moleculares incorporadas aos tecidos dos animais (Lawrence et al. 2012).

A energia produzida pela oxidação fisiológica é aproveitada pelo animal para mantença, como exemplo, estimulando o movimento de vários músculos para o bombeamento do sangue para o coração, diafragma e músculos intercostais colaborando na respiração, e homeotermia, manutenção da temperatura corporal e produção (Lawrence et al. 2012).

\subsection{Partição da energia na nutrição animal}

A energia utilizada pelos animais é obtida dos alimentos por processos digestivos e metabólicos, sendo os bovinos considerados energeticamente ineficientes, devido a perdas que ocorrem em cada estágio de assimilação de nutrientes (Marcondes et al. 2010).

Segundo Cabral et al. (2006) a energia nos alimentos pode ser expressa como energia bruta (EB), energia digestível (ED) ou nutrientes digestíveis totais (NDT), energia metabolizável (EM) e energia líquida (EL). A energia líquida é a forma mais correta para expressar a energia útil dos alimentos, pois, esta é efetivamente disponível para produção do animal. Portanto, sua determinação é laboriosa e de elevado custo, pois, no caso de animais de corte, deveria ser realizadas experimentações com cada alimento e determinar a energia retida ou depositada como matéria orgânica (proteína e gordura) no corpo dos animais (NRC 2000).

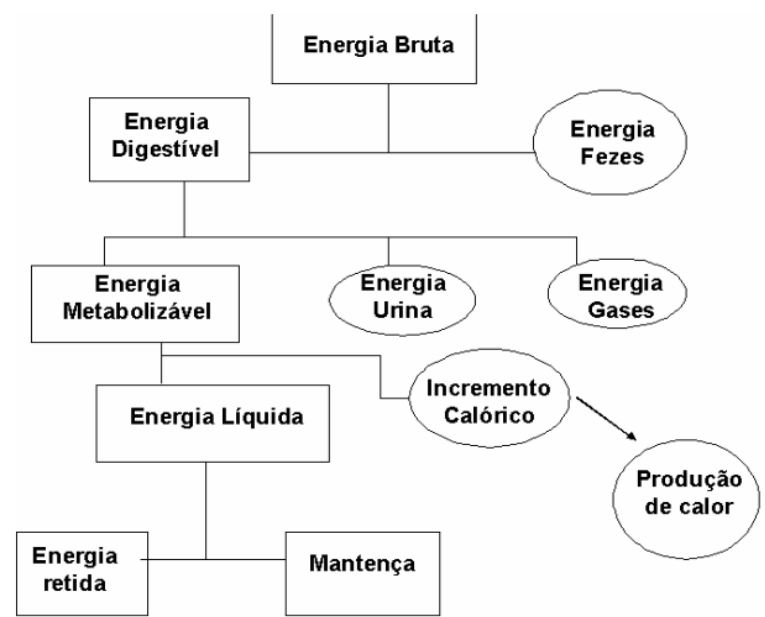

Figura 1. Partição de energia do alimento em ruminantes. Fonte: Berchielli et al. (2011).
Na Figura 1, (Berchielli et al. 2011), está demonstrado esquema da partição da energia no ruminante, conforme proposta do sistema de energia líquida utilizado pelo NRC de gado de corte e leite, explicitadas a seguir.

A energia é essencial para sustentar todos os processos vitais do corpo, incluindo respiração, circulação, atividade dos músculos, manutenção de temperatura corporal, processos metabólicos, entre outras funções. Sua deficiência manifestase no retardamento do crescimento, falhas na reprodução e perdas de reservas corporais, reduzindo a produtividade animal (Freitas et al. 2006).

O conceito nutricional de mantença não é o mesmo que metabolismo basal, pois na mantença o animal não está em jejum. A energia metabolizável para mantença $(\mathrm{EMm})$ é definida como a taxa de produção de calor de um animal mantido em um ambiente termo neutro quando a taxa de consumo de energia metabolizável é exatamente o saldo da taxa de perda de calor (Lawrence et al. 2012).

A produção de calor $(\mathrm{PC})$ correspondente a EMm, engloba a produção de calor do animal alimentado, ou seja, considera o incremento calórico (IC). Já a ELm é obtida do animal em jejum, ou seja, sem a produção de calor vinda do incremento calórico. A EMm é sempre superior a ELm, pois o processo de comer, digerir e metabolizar o alimento requer energia e este acaba sendo liberado do animal como calor. Os principais contribuintes para produção de calor em um animal recebendo EMm podem estar relacionados ao processamento da dieta pelo animal como o trabalho realizado para mastigação do alimento, movimento do aparelho digestivo, calor de fermentação e o incremento calórico associado a transformação dos nutrientes, contribuindo para manter a temperatura corporal, e outras atividades como o processo de circulação, respiração, locomoção e o custo energético para a renovação de tecidos (Lawrence et al. 2012).

A ELm pode sofrer influência de vários fatores como: idade, peso, raça, espécie, sexo, estágio fisiológico, nutrição previamente recebida e condições ambientais. Nos bovinos destinados à produção de carne, as exigências de energia para mantença podem corresponder a $70 \%$ das exigências totais de energia dos animais (NRC $\underline{2000)}$. 


\subsection{Técnicas para o estudo do metabolismo energético}

Sahlu et al. (1989) avaliaram o gasto energético de 90 carneiros, com peso inicial de $23,1 \mathrm{~kg}$, mantidos em pastagem dividida em 4 piquetes de 1,2 ha (15 ou 30 cordeiros/ha). A Figura 2 ilustra a resposta da forragem disponível para lotação taxa e período de pastejo. $\mathrm{O}$ valor de forragem disponível aumentou durante o primeiro período de pastejo para ambas as taxas de lotação e continuou a aumentar sob a baixa lotação no período 2.

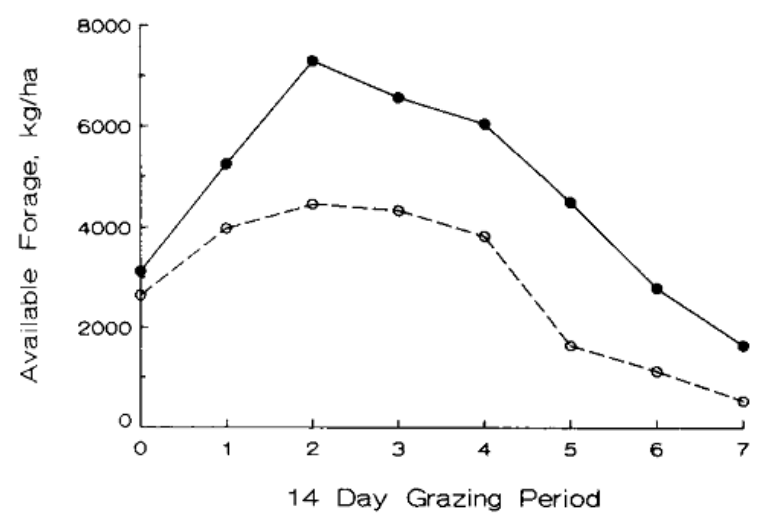

Figura 2. Forragem disponível para pastejo por 15 (__ ou 30 (----) cordeiros por hectare. Fonte: Sahlu et al. $\underline{(1989)}$.

Os autores observaram ganho de peso máximo (223 g/d), durante o período 3, seguido por um declínio para $184 \mathrm{~g} / \mathrm{d}$ no período 6 . Carneiros na alta taxa de lotação perderam quase duas vezes mais peso quando comparados àqueles sobre baixa taxa de lotação, durante o período 6 . O desempenho do crescimento recuperou no período $7(104 \mathrm{~g} / \mathrm{d})$, em resposta ao crescimento acelerado da forragem (Tabela 1$)$.

A Figura 3 ilustra o aumento na produção de calor associada com aumento da concentração de FDN da forragem verde. Isto sugere que a diminuição da qualidade do pasto pode resultar em alterações comportamentais que contribuem para o aumento da produção de calor (Sahlu et al. 1989).

Tabela 1. Resumo da taxa de lotação, ganho de peso e produção de calor dos ovinos utilizados no experimento.

\begin{tabular}{lcc}
\hline \multirow{2}{*}{ Característica } & \multicolumn{2}{c}{ Tratamento } \\
\cline { 2 - 3 } & 32,0 & 31,8 \\
\hline Peso vivo, $\mathrm{kg}$ & -1 & -18 \\
Ganho, g/d & 173,2 & 200,8 \\
Produção de calor, kcal/(kg & & \\
PV $^{0,75} /$ dia) &
\end{tabular}

Fonte: Sahlu et al. (1989).

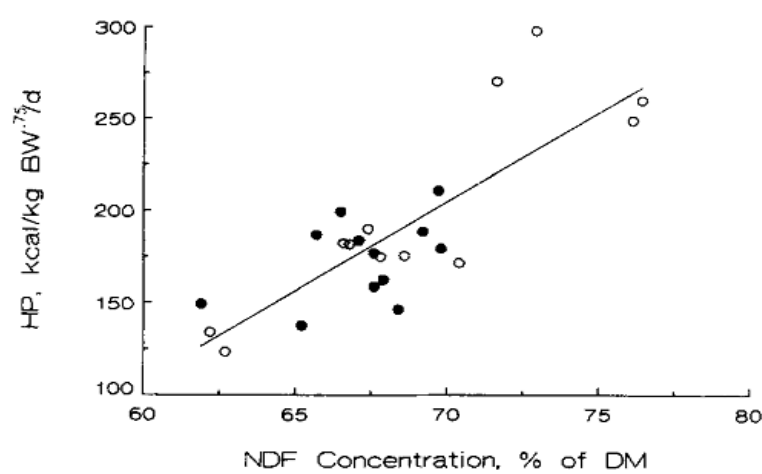

Figura 3. Razão entre a concentração de FDN na forragem verde disponível e da produção de calor (PC) de carneiros em baixa (*) e alto (O) taxas de lotação. Fonte: $\underline{\text { Sahlu et al. }}$ $\underline{(1989)}$

Utilizando 72 caprinos (2 machos e 70 fêmeas lactantes), Lachica et al. (1997) estimaram os gastos de energia durante as quatro estações do ano (outono, primavera, inverno e verão). As atividades foram divididas em várias categorias principais: pastejo, definido como o tempo gasto na procura e ingestão de forragem; em pé, definida como o movimento de um lugar para outro sem pastejo, em descanso, definida como ausência de atividade (em pé ou deitado), e outros (socialização). Pastoreio, caminhar e ficar em pé foram as principais atividades das cabras durante o período de estudo, representando, em média, 57, 27, e 13\%, respectivamente (Tabela 2). Atividade de pastejo subiu para a máxima (70\%) no inverno e diminuiu durante a primavera e o outono ( 52 e $48 \%$, respectivamente). Uma tendência semelhante foi observada para a caminhada (26, 22 e $21 \%$ durante todo o inverno, primavera e outono).

Tabela 2. Valores médios das atividades de caprinos devido à mudança na sazonalidade.

\begin{tabular}{|c|c|c|c|c|c|}
\hline & Pastejand & aminhanc & Em pé & Deitado & Outros \\
\hline & \multicolumn{5}{|c|}{$(\%)$} \\
\hline Outono & 48,4 & 20,9 & 19,0 & 11,5 & 0,2 \\
\hline Primavera & 70,0 & 26,4 & 2,2 & 0 & 1,5 \\
\hline Inverno & 51,5 & 22,0 & 18,5 & 7,4 & 0,7 \\
\hline Verão & --- & 36,8 & --- & --- & --- \\
\hline Média & 56,6 & 26,5 & 13,2 & 6,3 & 0,8 \\
\hline
\end{tabular}

Fonte: Lachica et al. (1997).

A distância percorrida diariamente pelos caprinos (Tabela 3 ) oscilou de $5.763 \mathrm{~m}$ no verão para $3482 \mathrm{~m}$ no outono, com uma média anual de $4.295 \mathrm{~m}$, o que representa uma velocidade diária média anual de 10,8m/min. A atividade de caminhada chegou ao pico no verão e, em seguida, caiu nas outras estações do ano, com um mínimo no outono. A média anual vertical (subida ou descida) foi de $168 \mathrm{~m}$ (Lachica et al. 
1997). De acordo com os autores, a produção de calor estimado devido à locomoção (Tabela 4) variou $56,9-34,8 \mathrm{~kJ} / \mathrm{kg}^{0.75}$ por dia no verão e outono.

Tabela 3. Médias diárias de atividades de locomoção de caprinos à pasto.

\begin{tabular}{|c|c|c|c|c|}
\hline & $\begin{array}{l}\text { Гempo gastc } \\
\text { para pastejar }\end{array}$ & $\begin{array}{l}\text { Distância } \\
\text { caminhada }\end{array}$ & $\begin{array}{c}\text { Subida ou } \\
\text { descida } \\
\text { vertical }\end{array}$ & $\begin{array}{c}\text { Velocidade } \\
\text { média }\end{array}$ \\
\hline & (h) & (m) & (m) & $(\mathrm{m} / \mathrm{min})$ \\
\hline Outono & $5,7 a$ & $3.482 \mathrm{a}$ & $139 a$ & $10,2 \mathrm{a}$ \\
\hline Primavera & $6,0 \mathrm{ab}$ & $4.137 \mathrm{ab}$ & $181 \mathrm{a}$ & $11,5 \mathrm{a}$ \\
\hline Inverno & $7,7 \mathrm{~b}$ & $3.799 a$ & $197 a$ & $8,2^{\mathrm{a}}$ \\
\hline Verão & $7,2 \mathrm{ab}$ & $5.763 b$ & $153 a$ & $13,3 \mathrm{a}$ \\
\hline Média anual & 6,7 & 4.295 & 168 & 10,8 \\
\hline
\end{tabular}

*Dentro da mesma coluna, letras diferentes são significativamente diferentes $(\mathrm{P}<0,05)$. Fonte: $\underline{\text { Lachica et }}$ al. (1997)

Palhano et al. (2006) avaliaram as estratégias de alimentação de bovinos em pastejo, quatro novilhas da raça Holandês Preto e Branco foram mantidas em pastagem de capim-mombaça (Panicum maximum Jacq.) com cinco alturas de dossel. $(60,80,100,120$ e $140 \mathrm{~cm})$. Os autores verificaram que as ofertas de forragem foram superiores a $300 \mathrm{~m}^{3} \mathrm{UA}^{-1}$ a partir da altura de 80 $\mathrm{cm}$. Quando expressa em porcentagem do peso vivo, a oferta de forragem excedeu o recomendado por Hodgson (1990) que apontou que o desempenho animal seria otimizado com ofertas de 10 a $12 \mathrm{~kg}$ de MS.100 kg de PV ${ }^{-1}$ (Tabela 5).

Como resposta aos tratamentos, observou-se que, com o aumento em altura do dossel, o número de estações alimentares por minuto foi menor, de 5,6 a 1,5 da menor para a maior altura (Figura 4). Esse comportamento dos animais pode ser explicado pela maior disponibilidade de forragem nas maiores alturas de dossel, condição que, segundo Prache et al. 1998) pode não os motivar a trocar de estação alimentar.

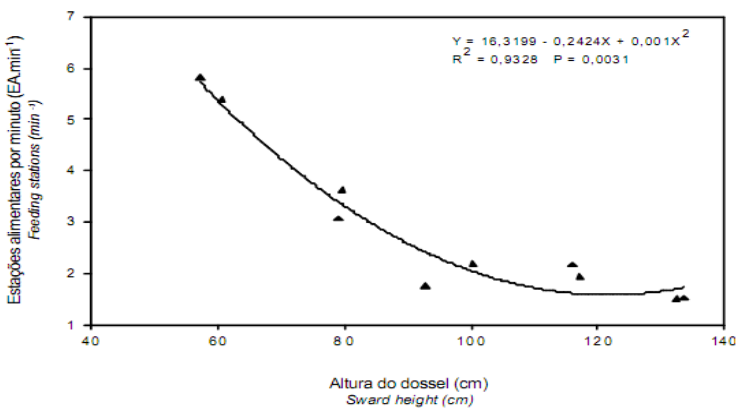

Figura 4. Relação altura do dossel $(\mathrm{cm}) \times$ número de estações alimentares por minuto visitadas por novilhas holandesas $\left(\mathrm{EA} \mathrm{min}^{-1}\right.$ ) em pastagem de capim-mombaça. Fonte: Palhano et al. (2006).

Tabela 4. Custo de energia para locomoção de caprinos em pastejo durante as diferentes estações do ano.

\begin{tabular}{lccc}
\hline & Peso vivo & $\begin{array}{c}\text { Produção de } \\
\text { calor }\end{array}$ & $\begin{array}{c}\text { Produção de } \\
\text { calor para } \\
\text { mantença }{ }^{1}\end{array}$ \\
\cline { 2 - 4 } & $(\mathrm{kg})$ & $\left(\mathrm{kJ}^{\prime} / \mathrm{kg}^{0,75}\right)$ & $(\%)$ \\
\hline Outono & 37 & $34,8 \mathrm{a}$ & $8,7 \mathrm{a}$ \\
Primavera & 35 & $41,4 \mathrm{ab}$ & $10,3 \mathrm{ab}$ \\
Inverno & 40 & $40,7 \mathrm{ab}$ & $10,1 \mathrm{ab}$ \\
Verão & 45 & $56,9 \mathrm{~b}$ & $14,2 \mathrm{~b}$ \\
Média anual & 38 & 43,5 & 10,8 \\
\hline *Dentro da & mesma & coluna, letras & diferentes são \\
significativamente diferentes (P<0,05). ${ }^{1} \mathrm{Mem}=401 \mathrm{~kJ} / \mathrm{kg}^{0,75}$ \\
por dia (Aguilera et al., 1990). Fonte: Lachica et al. $(1997)$.
\end{tabular}

Paralelamente à redução no número de estações alimentares por minuto, com o aumento na altura do dossel, houve acréscimo linear no número de passos entre as estações alimentares visitadas (Figura 5), com valores variando de 1,6 a 2,9 passos.

Tabela 5. Alturas efetivas do dossel na entrada e saída dos animais da pastagem, oferta de forragem, densidade volumétrica de forragem, de colmos + bainhas e de lâminas foliares e massas de forragem e de lâminas foliares do capim-mombaça

\begin{tabular}{|c|c|c|c|c|c|c|}
\hline \multirow{2}{*}{ Características estrutural do dossel } & \multicolumn{5}{|c|}{ Altura do dossel $(\mathrm{cm})$} & \multirow{2}{*}{-CV (\%) } \\
\hline & $\overline{60}$ & 80 & 100 & 120 & 140 & \\
\hline$\overline{\text { Altura de entrada }(\mathrm{cm})}$ & $58,9 \mathrm{e}$ & $79,3 \mathrm{~d}$ & $96,5 \mathrm{c}$ & $116,6 b$ & $133,0 \mathrm{a}$ & 2,5 \\
\hline Altura de saída $(\mathrm{cm})$ & $42,7 \mathrm{~d}$ & $59,6 \mathrm{c}$ & $94,4 \mathrm{~b}$ & $105,3 \mathrm{ab}$ & $114,1^{\mathrm{a}}$ & 4,8 \\
\hline Oferta de forragem $\left(\mathrm{m}^{3} \cdot \mathrm{UA}^{-1}\right)$ & $237 d$ & $293 c$ & $334 \mathrm{~b}$ & $410 \mathrm{a}$ & $431^{\mathrm{a}}$ & 3,4 \\
\hline Oferta de forragem $\left(\mathrm{kg} \mathrm{MS} / 100 \mathrm{~kg} \mathrm{PV}^{-1}\right)$ & $59,4 \mathrm{~b}$ & $66,8 \mathrm{ab}$ & $76,6 a b$ & $89,0 \mathrm{ab}$ & $104,4^{\mathrm{a}}$ & 14,4 \\
\hline Oferta de lâminas (kg MS/100 kg PV ${ }^{-1}$ ) & $9,9 \mathrm{c}$ & $21,1 \mathrm{bc}$ & $28,8 \mathrm{~b}$ & $35,7 \mathrm{ab}$ & $46,5^{\mathrm{a}}$ & 20,3 \\
\hline Densidade (kg MS.m³) & $1,26 \mathrm{a}$ & $1,14 \mathrm{a}$ & $1,10 \mathrm{a}$ & $1,09 \mathrm{a}$ & $1,22^{\mathrm{a}}$ & 15,8 \\
\hline Densidade de colmos (kg MS.m ${ }^{-3}$ ) & $0,45 \mathrm{a}$ & $0,34 \mathrm{a}$ & $0,33 \mathrm{a}$ & $0,41 \mathrm{a}$ & $0,41^{\mathrm{a}}$ & 25,2 \\
\hline Densidade de lâminas (kg MS.m ${ }^{-3}$ ) & $0,21 \mathrm{~b}$ & $0,36 \mathrm{ab}$ & $0,43 \mathrm{a}$ & $0,44 \mathrm{a}$ & $0,54^{\mathrm{a}}$ & 19,0 \\
\hline Massa de forragem (kg MS.ha-1) & $7,569 \mathrm{c}$ & $9,130 \mathrm{bc}$ & $11,063 \mathrm{bc}$ & $13,126 \mathrm{ab}$ & $17,247 \mathrm{a}$ & 13,2 \\
\hline Massa de lâminas $\left({\left.\mathrm{kg} \mathrm{MS} . h a^{-1}\right)}^{-1}\right.$ & $1,399 d$ & 2,911cd & $4,114 \mathrm{bc}$ & $5,328 \mathrm{~b}$ & $7,678^{\mathrm{a}}$ & 17,1 \\
\hline
\end{tabular}

*Médias seguidas da mesma letra, na mesma linha, não diferem $(\mathrm{P}<0,05)$ pelo teste Ducan. Fonte: Palhano et al. (2006). 
Esse comportamento está de acordo com as observações de Prache et al. (1998), segundo as quais, em condições de menor disponibilidade de forragem, os animais caminham menos entre estações alimentares sucessivas, aumentando o número de estações alimentares visitadas, em comparação às situações de ofertas mais elevadas.

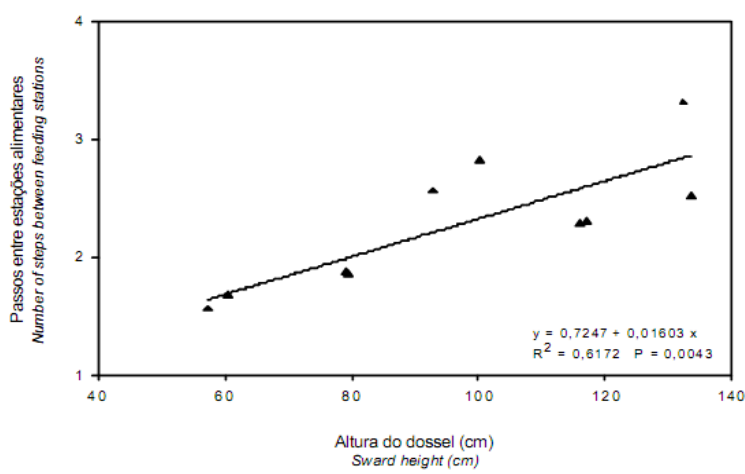

Figura 5. Relação altura do dossel $(\mathrm{cm}) \times$ número de passos entre estações alimentares de novilhas holandesas em pastagem de capim-mombaça. Fonte: Palhano et al. (2006).

Considerando ainda o aproveitamento da estação alimentar pelo animal em pastejo, ao relacionar o número de bocados ao de estações alimentares em diferentes alturas do dossel, obtevese uma relação quadrática (Figura 6), aumentando a partir das menores alturas de dossel até a altura de $100 \mathrm{~cm}$ e depois diminuindo. A fase ascendente do modelo, de 60 a $100 \mathrm{~cm}$ de altura, está de acordo com a relação teórica entre a riqueza da estação alimentar e sua intensidade de uso (Charnov 1976). No entanto, a fase descendente, de 120 a $140 \mathrm{~cm}$, comprova a possibilidade de interferência da estrutura do dossel sobre o pastejo. A utilização das estações alimentares tornar-se-ia limitada em condições de dossel com forragem demasiadamente dispersa em seus estratos superiores, em virtude do maior tempo destinado à mastigação e manipulação da forragem, o que limitaria a apreensão de novos bocados (Prache et al. 1998)

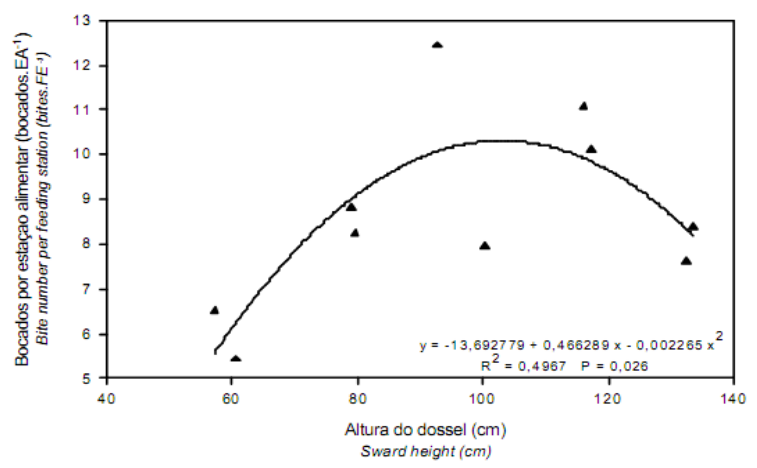

Figura 6. Relação altura do dossel $(\mathrm{cm}) \times$ número de bocados por estação alimentar (bocados.EA ${ }^{-1}$ ) em capimmombaça. Fonte: Palhano et al. (2006).
Apesar do aumento da distância percorrida entre estações alimentares com o incremento na altura do dossel os animais passaram a apresentar menor deslocamento total durante os testes de pastejo (Figura 7), bem como velocidades de deslocamento decrescentes (Figura 8), como consequência da maior disponibilidade de forragem em pastagens mais altas. Esta situação levou os animais a permanecer mais tempo nas estações alimentares, o que está de acordo com Bailey et al. (1996). Nas menores alturas, portanto, os animais deslocam-se mais e a passos mais velozes. Essa mudança na estratégia de procura da forragem pelo animal, em situação de forragem limitante, provavelmente visa aumentar a taxa de encontro de bocados potenciais na pastagem (Prache et al. 2009), com o intuito de manter níveis satisfatórios de consumo.

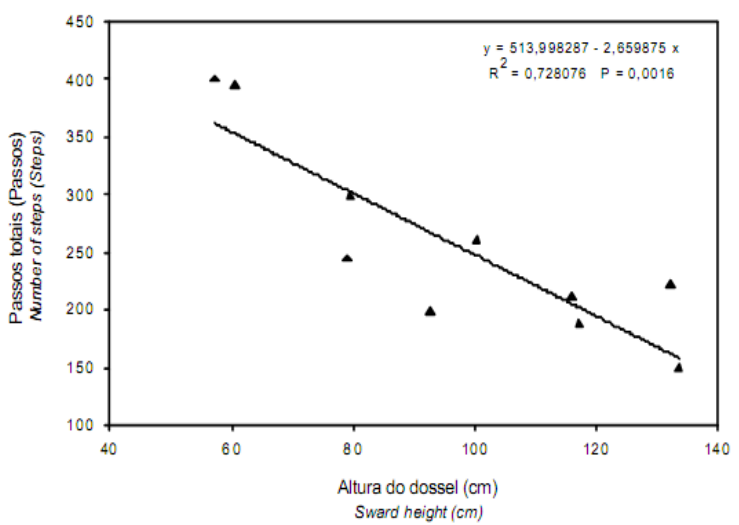

Figura 7. Relação altura do dossel $\times$ número total de passos em pastagem de capim-mombaça. Fonte: Palhano et al. $\underline{(2006)}$.

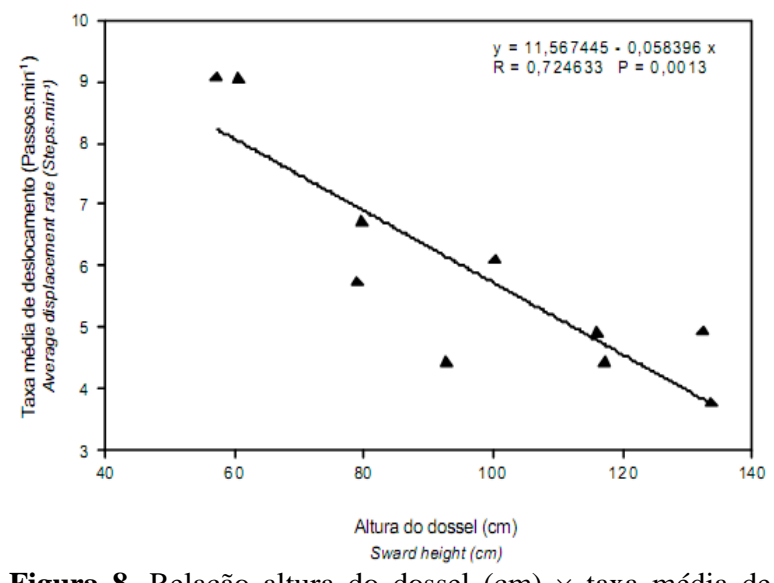

8. Relação altura do dossel $(\mathrm{cm}) \times$ taxa média de deslocamento (passos. $\mathrm{min}^{-1}$ ) de novilhas holandesas em pastagem de capim-mombaça. Fonte: Palhano et al. (2006).

Como consequência da combinação de estratégias de pastejo, houve redução da área utilizada por unidade de tempo com o aumento da altura do dossel (Figura 9), de modo que os 
valores variaram de $\quad 6,24$ a $\quad 2,70$ $\mathrm{m}^{2}$ /animal/minuto (Palhano et al. 2006).

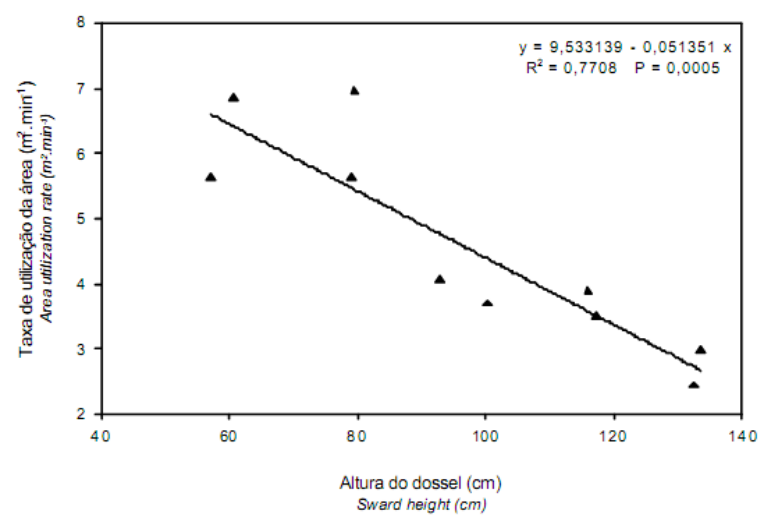

Figura 9. Relação altura do dossel $(\mathrm{cm}) \times$ taxa de utilização da área $\left(\mathrm{m}^{2} \cdot \mathrm{min}^{-1}\right)$ em pastagem de capim-mombaça. Fonte: Palhano et al. (2006).

Baggio et al. (2008) avaliaram o comportamento de pastejo de novilhos de corte, utilizando no experimento pastagem de azevém anual (Lolium multiflorum Lam) e aveia-preta (Avena strigosa Schreb) submetida a quatro alturas de manejo $(10,20,30$ e $40 \mathrm{~cm})$. A massa de forragem aumentou de forma linear e a oferta de forragem, de forma exponencial, com o aumento da altura do pasto, o que confirma a criação de diversos ambientes de alimentação (Figura 10). Observou-se maior tempo de pastejo na altura de $10 \mathrm{~cm}$. De acordo com Baggio et al. (2008) esse fato pode estar relacionado à menor altura do pasto e à baixa massa de forragem.
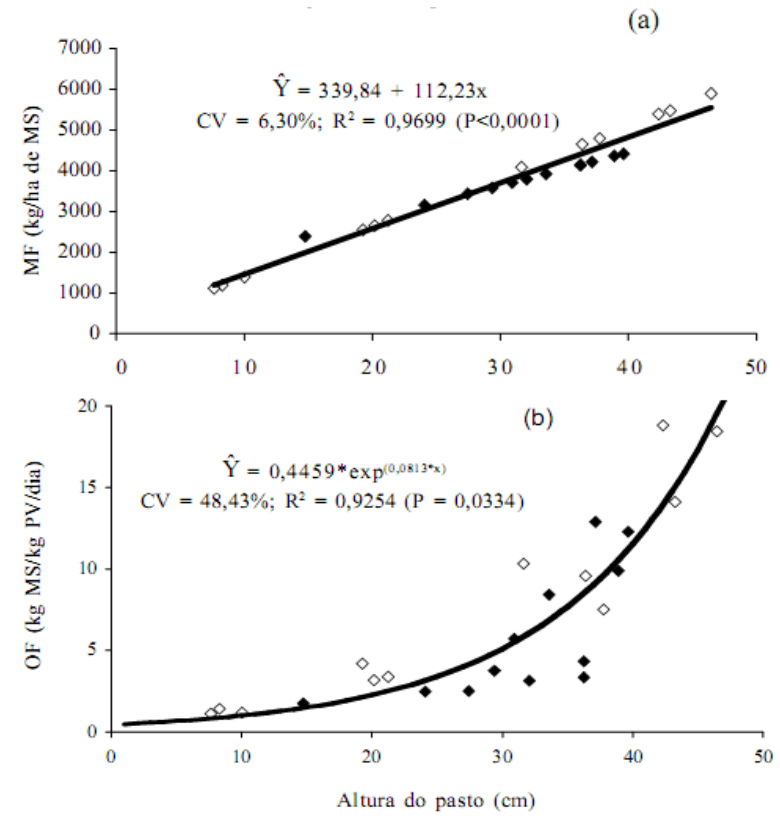

Figura 10. Massa de forragem (MF; a) e oferta de forragem $(\mathrm{OF} ; \mathrm{b})$ em diversas alturas de manejo em pastagem de azevém anual e aveia-preta nos dois estádios avaliados. Fonte: Baggio et al. (2008).
O aumento do tempo de pastejo (Figura 11) é uma estratégia dos animais de compensar a diminuição da massa do bocado e aumentar o consumo de forragem em situações de baixa disponibilidade de forragem (Laca et al. 1992). Sarmento et al. (2003) descreveram tendência similar, ou seja, em pastos mantidos a $10 \mathrm{~cm}$ de altura, os animais despendem aproximadamente 1 hora a mais de pastejo em comparação ao tempo gasto em pastos de $40 \mathrm{~cm}$.

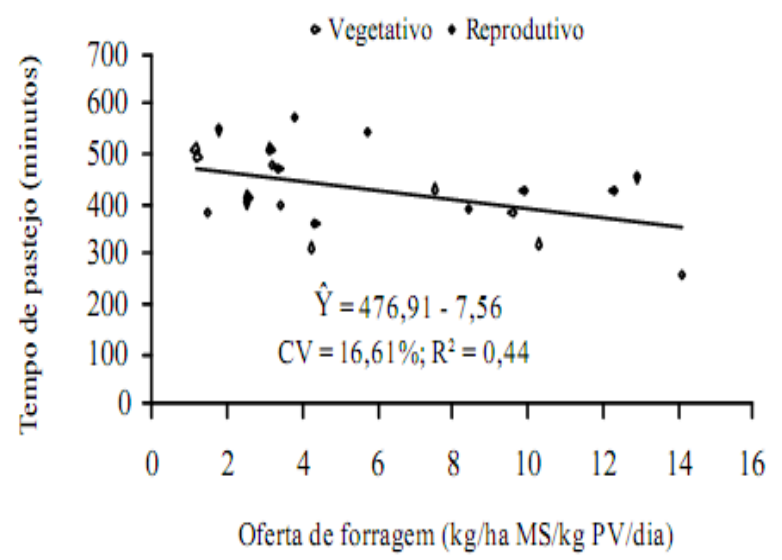

Figura 11. Relação entre tempo de pastejo e oferta de forragem em pastagem de azevém anual e aveia-preta nos estádios vegetativo e reprodutivo. Fonte: Baggio et al. (2008).

A distribuição das atividades diárias dos animais em pastejo (Figura 12) comprova que, em ambos os estádios avaliados, o pico da atividade de pastejo ocorreu ao entardecer, no período das 17 às $19 \mathrm{~h}$, o que resultou em refeições com mais longa duração ao final da tarde. Segundo Prache (2009), os animais intensificam suas estratégias de ingestão de nutrientes de acordo com os teores de carboidratos não-fibrosos e matéria seca nas plantas no período ainda com luminosidade do dia. No período entre o final da tarde e o início da noite, os bocados realizados pelos animais contêm mais nutrientes que os bocados coletados em outros horários, o que significa que o pastejo ao entardecer é eficiente e favorável se considerada a proporção nutriente ingerido/nutriente despendido (Baggio et al. 2008).

Observa-se, na figura 13 , que a maior oferta de massa de lâminas foliares nos pastos com maiores alturas ocasionou redução do tempo de duração da refeição (Baggio et al. 2008), pois os animais atingem o ponto de saciedade em menor espaço de tempo (Carvalho et al. 2004; Carvalho et al. 2008). 

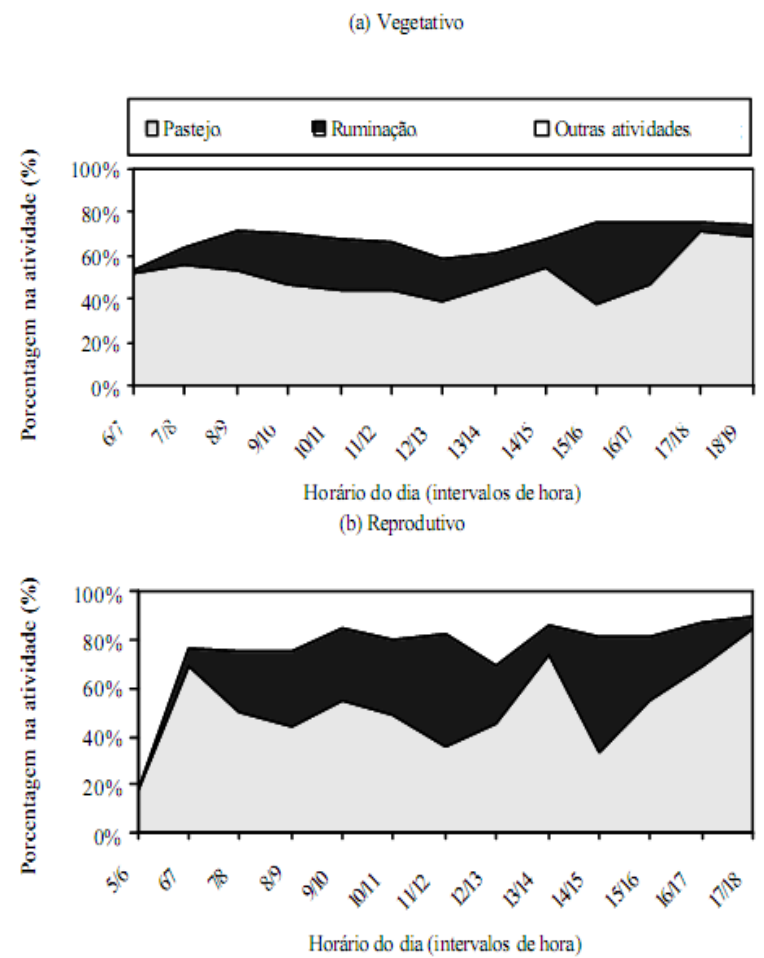

Figura 12. Distribuição percentual das atividades diurnas de novilhos em pastagem de azevém anual e aveia-preta nos estádios vegetativo (a) e reprodutivo (b). Fonte: Baggio et al. (2008).

Brosh et al. (2010) determinaram o custo de energia associados às atividades de vacas de corte. O objetivo central era comparar o custo de energia, utilizando grandes lotes, com aqueles obtidos em um estudo realizado por Brosh et al. (2006) realizado em parcelas menores. As medições foram realizadas em três estações: março (vacas pastando em 135 ha de forragem de alta qualidade $(11,4 \mathrm{MJ} / \mathrm{kg}$ de $\mathrm{ME}) \mathrm{e}$, em maio e setembro (vacas não-lactantes em 78 ha de forragem de baixa qualidade (6,2 MJ/kg do ME). Foram utilizados três modelos estatísticos: 1) o modelo completo, 2) como um modelo, mas sem mês e no mês $\times$ interação horas e 3 ) como o modelo 2, mas sem tempo de dia. Os modelos foram definidos como se segue:

1) $\mathrm{HPijkm}=\mathrm{K}+\mathrm{Ai}+\mathrm{ACm}+\mathrm{DH}+\mathrm{DV}+\mathrm{Mj}+(\mathrm{Mj} \times \mathrm{Hk})+\mathrm{e}$,

2) $\mathrm{HPikm}=\mathrm{K}+\mathrm{Ai}+\mathrm{ACm}+\mathrm{DH}+\mathrm{DV}+\mathrm{Hk}+\mathrm{e}$,

3) $\mathrm{HPim}=\mathrm{K}+\mathrm{Ai}+\mathrm{ACm}+\mathrm{DH}+\mathrm{DV}+\mathrm{e}$,

onde $\mathrm{HP}=$ produção de calor medido $(\mathrm{kJ} \mathrm{kg}$ de BW-0,75 $\left.\mathrm{d}^{-1}\right), \quad \mathrm{K}=$ constante; $\mathrm{Ai}=$ efeito aleatório de vaca $\mathrm{i}, \mathrm{i}=1$ a $17 ; \mathrm{ACM}=$ efeito fixo da atividade $\mathrm{m}, \mathrm{m}=1$ a $4 ; \mathrm{DH}=$ velocidade horizontal $\left(\mathrm{km} \mathrm{d}^{-1}\right) ; \mathrm{DV}=$ velocidade vertical positiva ( $\mathrm{km} \mathrm{d}-1) ; \mathrm{Mj}=$ efeito fixo do mês $\mathrm{j}, \mathrm{j}=1$ a $3 ; \mathrm{Hk}=$ efeito fixo de horas do dia $\mathrm{k}, \mathrm{k}=0 \mathrm{a}$ 23 , e e $=$ efeito residual aleatória.

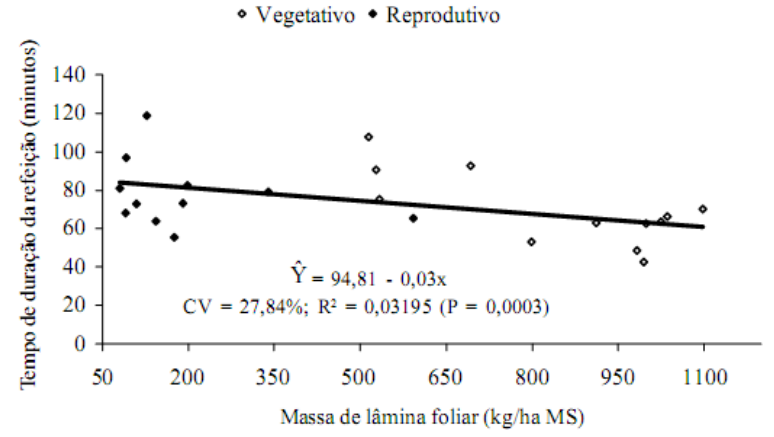

Figura 13. Relação entre o tempo de duração da refeição e a massa de lâmina foliar em pastagem de azevém anual e aveia-preta nos estádios vegetativo e reprodutivo. Fonte: Baggio et al. (2008).

$\mathrm{Na}$ tabela 6, observa-se que a forragem amostrada no início da primavera (março) foi de muito melhor qualidade do que a amostra no final do ano (maio e setembro), como refletido pela menor FDN e maior PB e concentrações de março (Brosh et al. 2010).

Tabela 6. Biomassa, composição química das amostras de forragem (base MS) tomadas em março (início da primavera), maio (início do verão) e setembro (final do verão).

\begin{tabular}{lccc}
\hline \multicolumn{1}{c}{ Item } & Março & Maio & Setembro \\
\hline Biomassa, kg/ha & $1,084 \mathrm{a}$ & $2,415 \mathrm{~b}$ & $1,104 \mathrm{a}$ \\
FDN, g/kg & $364 \mathrm{a}$ & $763 \mathrm{~b}$ & $655 \mathrm{~b}$ \\
$\mathrm{~PB}, \mathrm{~g} / \mathrm{kg}$ & $195 \mathrm{~b}$ & $54 \mathrm{a}$ & $46 \mathrm{a}$ \\
EM, MJ/kg & $11,36 \mathrm{~b}$ & $6,18 \mathrm{a}$ & $6,20 \mathrm{a}$ \\
\hline
\end{tabular}

a-c Diferem entre si, na mesma linha, ao nível de 5\% de probabilidade $(\mathrm{P}<0,05)$. Fonte: Brosh et al. (2010).

Na tabela 7, o coeficiente de custo de energia associada a um estado de atividade foi de $44 \mathrm{~kJ}$ $\mathrm{kg}$ de $\mathrm{BW}_{-}{ }^{0,75} \mathrm{~d}^{-1}$ para a posição (estimativa média para os três modelos), se o dobro para andar ocioso $\left(88 \mathrm{~kJ} k g\right.$ de $\left.\mathrm{BW}^{-0,75} \mathrm{~d}^{-1}\right)$. O coeficiente de custo de energia para pastagem (94 $\mathrm{kJ} \mathrm{kg} \mathrm{de} \mathrm{BW}^{-0,75} \mathrm{~d}^{-1}$ ) foi de cerca de $7 \%$ maior do que para andar ocioso (Brosh et al. 2010).

Tabela 7. Coeficientes de incremento de energia acima do estado de mentir-down da atividade $\left(\mathrm{kJ} \mathrm{kg} \mathrm{de} \mathrm{BW}^{-0,75} \mathrm{~d}^{-1}\right)$ e locomoção (kJ $\mathrm{kg}$ de $\left.\mathrm{BW}^{-0,75} \quad \mathrm{~d}^{-1} \quad \mathrm{~km}^{-1}\right)$, conforme determinado por três modelos estatísticos.

\begin{tabular}{lcccccc}
\hline Item & \multicolumn{3}{c}{ Atividade } & \multicolumn{2}{c}{ Locomoção } & \multirow{2}{*}{$\mathrm{R}^{2}$} \\
\cline { 1 - 6 } Modelo & Em pé & Caminhando Pastejando & Hoizontal & Vetical & \\
\hline 1 & 43,2 & 86,1 & 89,4 & 2,80 & 21,42 & 0,60 \\
2 & 42,7 & 84,5 & 90,8 & 2,80 & 22,22 & 0,58 \\
3 & 46,2 & 92,4 & 103,2 & 2,92 & 27,92 & 0,55 \\
Média & 44,03 & 87,67 & 94,47 & 2,84 & 23,85 & \\
CV,\% & 2,48 & 2,75 & 4,64 & 1,45 & 8,58 & \\
\hline
\end{tabular}

Fonte: Brosh et al. (2010).

De acordo com Brosh et al. (2010), o tempo gasto deitado variou 5,4-7,1 h/d e não diferiram entre os meses avaliados. O tempo em pé foi 
responsável por 6,6-9,0 h/d e foi menor em março que em maio e setembro. Em contraste, o tempo de pastejo foi maior em março $(11,7 \mathrm{~h} / \mathrm{d})$ do que em maio e setembro. $\mathrm{O}$ tempo gasto andar ociosos aumentou, de março a maio e aumentou ainda mais para $1,1 \mathrm{~h} / \mathrm{d}$ em Setembro (Tabela 8).

Teixeira et al. (2011) conduziram um experimento com o objetivo de avaliar o padrão de deslocamento e a permanência de bovinos em pastos de Brachiaria decumbens diferidos por 95 dias sob quatro estratégias de aplicação de nitrogênio $(0-0,100-0,50-50,0-100 \mathrm{~kg}$ de N.ha $\left.{ }^{1}\right)$ no início e no final do período chuvoso. Durante o período de utilização dos pastos diferidos, na estação seca, foram avaliadas a produção, algumas características estruturais da forragem e o padrão de deslocamento. Para avaliação dessas variáveis, foram aplicados dez testes de pastejo de 45 minutos utilizando-se quatro novilhos e, para avaliação de tempo de permanência, foram utilizadas 14 novilhas da raça Girolanda, monitoradas a cada 10 minutos durante 24 horas.

Maiores valores de massa de forragem total, de lâminas foliares e disponibilidade de matéria seca verde (DMSV) foram encontradas, Teixeira et al. (2011), nos pastos cuja estratégia de adubação foi a aplicação de 100 $\mathrm{kg}$ de nitrogênio no final do período chuvoso (0-100) (Tabela 9).

Tabela 8. Tempo dedicado a vários estados de atividade e as distâncias de locomoção de vacas de corte, de acordo com o mês avaliado.

\begin{tabular}{lccc}
\hline Comportamento & Março & Maio & Setembro \\
\hline Atividade, h/d & & & \\
\hline Deitado & 5,43 & 6,23 & 7,07 \\
Em pé & $6,63 \mathrm{a}$ & $9,03 \mathrm{~b}$ & $8,42 \mathrm{~b}$ \\
Pastejando & $11,68 \mathrm{~b}$ & $8,32 \mathrm{a}$ & $7,43 \mathrm{a}$ \\
Andar ocioso & $0,18 \mathrm{a}$ & $0,40 \mathrm{~b}$ & $1,07 \mathrm{c}$ \\
\hline Locomoção, m/d & & & \\
Horizontal enquanto pastejavam & $2,327 \mathrm{~b}$ & $1,832 \mathrm{a}$ & $1,551 \mathrm{a}$ \\
Horizontal enquanto caminhavam & $315 \mathrm{a}$ & $677 \mathrm{a}$ & $1,999 \mathrm{~b}$ \\
Horizontal, total & $2,642 \mathrm{a}$ & $2,509 \mathrm{a}$ & $3,550 \mathrm{~b}$ \\
Subida enquanto pastejavam & $112 \mathrm{~b}$ & $80 \mathrm{a}$ & $68 \mathrm{a}$ \\
Subida enquanto caminhavam & $8 \mathrm{a}$ & $5 \mathrm{a}$ & $56 \mathrm{~b}$ \\
Subida, total & $120 \mathrm{~b}$ & $85 \mathrm{a}$ & $124 \mathrm{~b}$ \\
\hline
\end{tabular}

a-c Diferem entre si, na mesma linha, ao nível de $5 \%$ de probabilidade ( $\mathrm{P}<0,05)$. Fonte: Brosh et al. (2010).

Foram encontradas as maiores massas de lâminas de folhas nos pastos adubados com 100 $\mathrm{kg}$ de $\mathrm{N}$ no final do período chuvoso (Tabela 10), calculando-se um aumento de $43 \%$ em relação aos pastos que não receberam adubo (0-0), confirmando o rápido efeito do nitrogênio em aumentar a taxa de fotossíntese das plantas e o maior fornecimento de foto assimilados para os tecidos de crescimento (Teixeira et al. 2011).

Tabela 9. Massa de forragem e de lâminas foliares, altura do pasto, da planta estendida, índice de acamamento e coeficiente de variação dos pastos de Brachiaria decumbens diferidos, sob quatro estratégias de adubação nitrogenada.

\begin{tabular}{|c|c|c|c|c|c|}
\hline \multirow{2}{*}{ Variáveis } & \multicolumn{4}{|c|}{ Estratégia de adubação nitrogenada ${ }^{1}$} & \multirow{2}{*}{$\mathrm{CV}(\%)$} \\
\hline & $0-0$ & $0-100$ & $50-50$ & $100-0$ & \\
\hline Massa de forragem (kg MS.ha $\left.{ }^{-1}\right)$ & $6,228 \mathrm{c}$ & $7,997 \mathrm{a}$ & $6,746 \mathrm{~b}$ & $6,273 c$ & 2,2 \\
\hline Massa de lâmina de folha (kg MS.ha-1) & $1,472 d$ & $3,427 \mathrm{a}$ & $2,774 \mathrm{~b}$ & $2,511 \mathrm{c}$ & 2,7 \\
\hline Disponibilidade de matéria verde $\left(\mathrm{kg} \cdot \mathrm{ha}^{-1}\right)$ & $5,510 \mathrm{~d}$ & $7,653 a$ & $6,392 b$ & $5,638 \mathrm{c}$ & 1,1 \\
\hline Altura do pasto $(\mathrm{cm})$ & $69,1 \mathrm{ab}$ & $73,2 a$ & $66,2 \mathrm{~b}$ & $73,3 \mathrm{a}$ & 3,2 \\
\hline Altura da planta estendida $(\mathrm{cm})$ & $93,8 \mathrm{c}$ & $127,8 \mathrm{a}$ & $115,3 b$ & $102,7 \mathrm{c}$ & 4,2 \\
\hline Índice de acamamento ${ }^{2}$ & $1,4 \mathrm{~b}$ & $1,7 \mathrm{a}$ & $1,7 \mathrm{a}$ & $1,4 \mathrm{~b}$ & 3,5 \\
\hline
\end{tabular}

Médias seguidas de letras minúsculas distintas na linha diferem $(\mathrm{P}<0,05)$ pelo teste Tukey.

${ }^{1}$ Estratégias de aplicação de nitrogênio (0-0, 100-0, 50-50, 0-100 kg de N.ha-1) no início e no final do período chuvoso, respectivamente. ${ }^{2}$ Quociente entre a altura da planta estendida e a altura do pasto. Fonte: $\underline{\text { Teixeira et al. (2011). }}$.

De acordo com Teixeira et al. (2011), o número de estações alimentares por minuto foi maior nas parcelas cuja estratégia de adubação foi a aplicação de $100 \mathrm{~kg}$ de $\mathrm{N}$ no final do período chuvoso (0-100), seguida da estratégia parcelada 50-50 (Figura 14). É possível que os animais tenham escolhido novas estações próximos, tendo em vista a maior possibilidade de seleção por lâminas de folhas, devido à alta digestibilidade da MS verde encontrada nestes pastos, resultando em maior número de estações alimentares em determinado espaço de tempo.

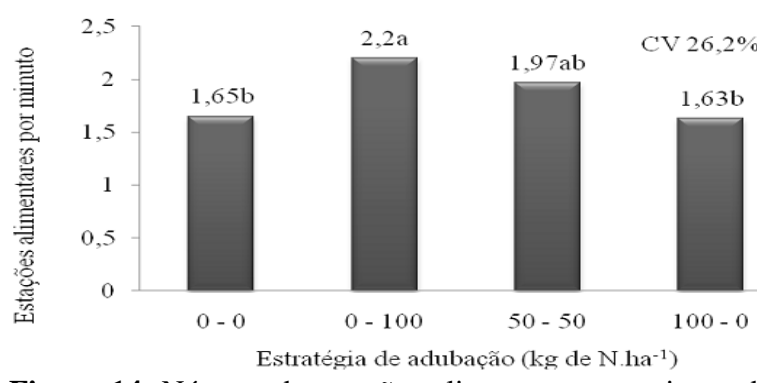

Figura 14. Número de estações alimentares por minuto de novilhos em pastos de Brachiaria decumbens diferidos sob quatro estratégias de adubação nitrogenada no início e no final do período chuvoso. Fonte: Teixeira et al. (2011). 
Para Teixeira et al. (2011), paralelamente ao aumento no número de estações alimentares por minuto para as estratégias de adubação: $100 \mathrm{~kg}$ de $\mathrm{N}$ aplicado no final do período chuvoso (0100) e parcelado (50-50), os animais passaram a apresentar maiores velocidades de deslocamento, expressa em número de passos por minuto, como consequência da maior dificuldade de seleção da forragem com maior grau de acamamento (Figura 15). Essa situação levou os animais a permanecerem menos tempo nas estações alimentares, deslocando-se mais e a passos mais velozes. Essa mudança na estratégia de procura da forragem pelo animal, em situação de limitação estrutural da forragem, provavelmente visa aumentar a taxa de encontro de bocados potenciais na pastagem (Prache 2009), com o intuito de manter níveis satisfatórios de consumo, porém, indica maior gasto energético no processo de colheita de forragem.

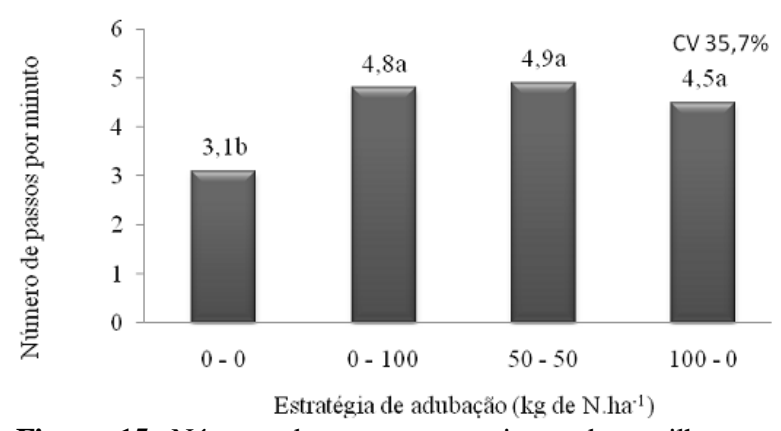

Figura 15. Número de passos por minuto de novilhos em pastos de Brachiaria decumbens diferidos, sob quatro estratégias de adubação nitrogenada no início e no final do período chuvoso, respectivamente. Fonte: Teixeira et al. $\underline{(2011)}$.

Tabela 10. Densidade volumétrica de forragem total, de lâminas de folhas, de colmo verde, e de forragem morta em pastos de Brachiaria decumbens diferidos, sob quatro estratégias de adubação nitrogenada.

\begin{tabular}{|c|c|c|c|c|c|}
\hline \multirow{3}{*}{ Estrato } & \multicolumn{4}{|c|}{ Estratégia de adubação nitrogenada ${ }^{1}$} & \multirow[b]{2}{*}{$\mathrm{CV}(\%)$} \\
\hline & $0-00$ & $0-100$ & $50-50$ & $100-0$ & \\
\hline & \multicolumn{4}{|c|}{ Densidade de forragem total (kg MS.cm.ha ${ }^{-1}$ ) } & \\
\hline A (acima de $40 \mathrm{~cm})$ & $13,6 \mathrm{c}$ & $29,5 \mathrm{a}$ & $15,6 \mathrm{c}$ & $19,8 \mathrm{c}$ & \\
\hline B (20-40 cm do solo) & $71,0 \mathrm{c}$ & $116,8 \mathrm{a}$ & $104,8 b$ & $86,4 \mathrm{c}$ & 2,2 \\
\hline \multirow[t]{2}{*}{$\mathrm{C}(0-20 \mathrm{~cm}$ do solo $)$} & $222,2, \mathrm{ac}$ & $221,6 \mathrm{a}$ & $207,1 \mathrm{~b}$ & $194,6 \mathrm{c}$ & \\
\hline & \multicolumn{4}{|c|}{ Densidade de lâminas de folhas (kg MS.cm.ha-1) } & \\
\hline A (acima de $40 \mathrm{~cm})$ & $11,6 \mathrm{c}$ & $26,0 \mathrm{a}$ & $13,7 \mathrm{bc}$ & $17,1 \mathrm{bc}$ & \\
\hline B (20-40 cm do solo) & $28,9 \mathrm{dc}$ & $65,9 \mathrm{a}$ & $57,1 \mathrm{~b}$ & $37,6 \mathrm{c}$ & 5,8 \\
\hline \multirow[t]{2}{*}{$\underline{\mathrm{C}(0-20 \mathrm{~cm} \text { do solo })}$} & $29,3 \mathrm{c}$ & $51,2 \mathrm{~b}$ & $58,5 \mathrm{a}$ & $59,8 \mathrm{a}$ & \\
\hline & \multicolumn{4}{|c|}{ Densidade de colmo verde (kg MS.cm.ha ${ }^{-1}$ ) } & \\
\hline A (acima de $40 \mathrm{~cm})$ & $2,1 \mathrm{a}$ & $3,5 \mathrm{a}$ & $1,8 \mathrm{a}$ & $2,8 \mathrm{a}$ & \\
\hline B (20-40 cm do solo) & $40,9 b$ & $47,9 \mathrm{a}$ & $45,2 \mathrm{a}$ & $46,6 \mathrm{a}$ & 3,2 \\
\hline \multirow[t]{2}{*}{$\mathrm{C}(0-20 \mathrm{~cm}$ do solo $)$} & $158,2 \mathrm{a}$ & $156,1 \mathrm{a}$ & $132,7 \mathrm{~b}$ & $105,3 \mathrm{c}$ & \\
\hline & \multicolumn{4}{|c|}{ Densidade de forragem morta (kg MS.cm.ha ${ }^{-1}$ ) } & \\
\hline A (acima de $40 \mathrm{~cm})$ & 0,0 & 0,0 & 0,0 & 0,0 & \\
\hline B (20-40 cm do solo) & $1,2 \mathrm{a}$ & $3,0 \mathrm{a}$ & $2,6 \mathrm{a}$ & $2,3 a$ & 11,1 \\
\hline $\mathrm{C}(0-20 \mathrm{~cm}$ do solo $)$ & $34,7 \mathrm{a}$ & $15,5 \mathrm{c}$ & $16,3 \mathrm{c}$ & $29,5 b$ & \\
\hline
\end{tabular}

Médias seguidas de letras minúsculas distintas na linha diferem $(\mathrm{P}<0,05)$ pelo teste Tukey. ${ }^{1}$ Aplicação de nitrogênio $(0-0$, 100-0, 50-50, 0-100 kg de N.ha-1 ) no início e no final do período chuvoso. Fonte: Teixeira et al. (2011).

O número de bocados por estação e por minuto foi menor para as estratégias de adução 0100 e 50-50 (Tabela 11), ao contrário dos resultados de números de estações alimentares e passos por minuto. Esse comportamento também pode ser explicado pela maior disponibilidade de matéria seca verde nessas parcelas, que provavelmente proporcionou maior profundidade e volume de bocado e consequentemente diminuiu a quantidade de bocados desferida por estação e por minuto (Teixeira et al. 2011).

Avaliando o tempo de permanência de pastejo entre os pastos diferidos com diferentes estratégias de adubação nitrogenada, verificaramse maiores valores para os pastos cuja estratégia de adubação, foi a aplicação de $100 \mathrm{~kg}$ de N no final do período chuvoso (0-100) (Figura 16). Segundo Teixeira et al. (2011), ao início da exploração de uma estação alimentar, o animal se defronta com escolhas como, por exemplo, quais tipos ou partes de uma planta colher, essas estratégias são fundamentais na definição do consumo em pastejo.

Vieira Júnior et al. (2011) avaliaram o comportamento ingestivo e desempenho de 27 cordeiras Santa Inês em pasto de capim-marandu, submetidos à diferentes taxas de lotação durante a estação chuvosa e de transição. Os animais foram distribuídos em um delineamento experimental inteiramente casualizado, com nove repetições. A área experimental com $4.500 \mathrm{~m}^{2}$ foi dividida em 45 piquetes de $100 \mathrm{~m}^{2}$. Os animais 
foram divididos em nove grupos com o mesmo peso inicial e submetidas a três taxas de lotação: 2, 3 e 4 cordeiros/piquete, o que correspondeu a 40, 60 e 80 cordeiros/ha, respectivamente.

Tabela 11. Número de bocados por minuto e por estação alimentar de novilhas leiteiras em pastos de Brachiaria decumbens diferidos sob quatro estratégias de adubação nitrogenada.

\begin{tabular}{lccccc}
\hline \multirow{2}{*}{ Variáveis } & \multicolumn{5}{c}{ Estratégia de adubação nitrogenada } \\
\cline { 2 - 6 } & $0-0$ & $0-100$ & $50-50$ & $100-0$ & $\begin{array}{c}\text { CV } \\
(\%)\end{array}$ \\
\hline $\begin{array}{l}\text { Bocados.min } \\
\text { Bocados.estação } \\
\text { alimentar }^{-1}\end{array}$ & $18,6 \mathrm{a}$ & $13,7 \mathrm{~b}$ & $17,3 \mathrm{a}$ & $16,9 \mathrm{a}$ & 19,2 \\
\hline
\end{tabular}

Médias seguidas de letras minúsculas distintas na linha diferem $(\mathrm{P}<0,05)$ pelo teste Tukey. ${ }^{1}$ Estratégias de aplicação de nitrogênio (0-0, 100-0, 50-50, 0-100 kg de N.ha-1) no início e no final do período chuvoso, respectivamente. Fonte: Teixeira et al. (2011).

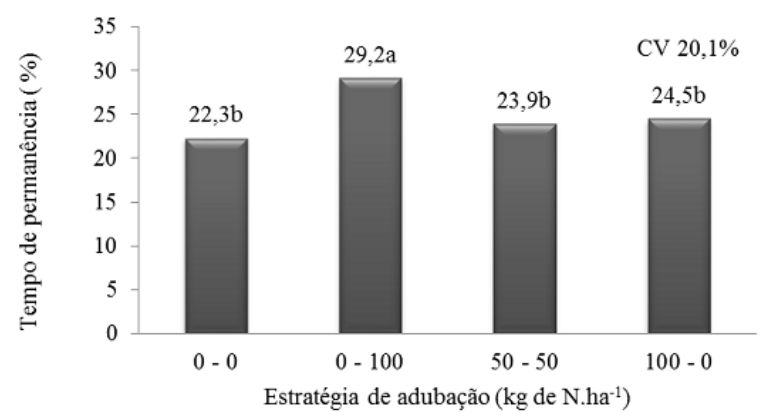

Figura 16. Tempo de permanência de pastejo de novilhas leiteiras em pastos de Brachiaria decumbens diferidos sob quatro estratégias de adubação nitrogenada no início e no final do período chuvoso. Fonte: Teixeira et al. (2011).

O tempo de pastejo (Figura 17) aumentou conforme as taxas de lotação, enquanto foi observada uma resposta inversa para ruminação e ócio. Como as atividades são mutuamente exclusivas, para 60 e 80 animais/ha, houve menos tempo para ruminação e redução de $41 \%$ no tempo de descanso, em comparação com a taxa de lotação mais baixo.

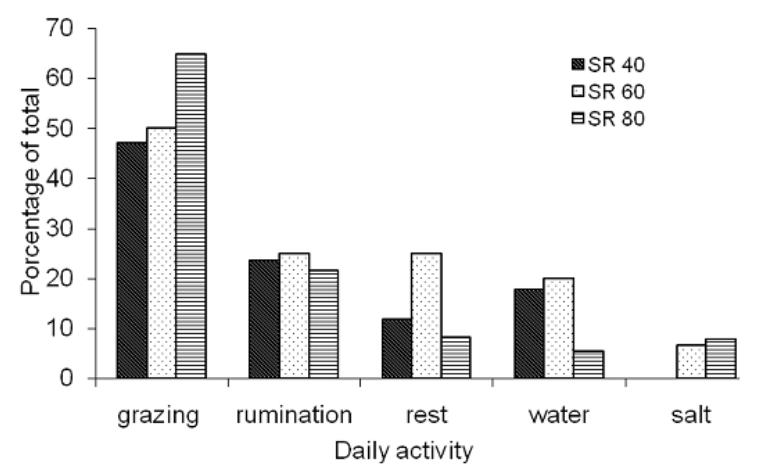

Figura 17. Comportamento de cordeiros em função das taxas de lotação no pasto de capim-marandu (SR) durante a estação chuvosa e transição. Fonte: Vieira Júnior et al. $\underline{(2011)}$.
De acordo com Vieira Júnior et al. (2011) houve efeito linear decrescente sobre o ganho médio diário (Figura 18), o que reduziu $1,101 \mathrm{~g}$ para cada unidade de aumento na taxa de lotação (animais/ha). Em contrapartida, o ganho médio diário foi positivamente relacionada com a oferta de forragem, especialmente para lâmina foliar verde, que aumenta com a redução do número de animais sob pastejo.

O maior GMD foi obtido a menor taxa de lotação, mas o maior ganho de peso por área ocorreu com 60 cordeiros/ha (426 kg/ha), com valores observados de 378 e $383 \mathrm{~kg} / \mathrm{ha}$ para abastecer as doses de 40 e 80 cordeiros/ha, respectivamente (Figura 19). A maior taxa de lotação não correspondeu ao maior ganho por área, provavelmente devido ao GMD inferior $(45,62 \mathrm{~g} / \mathrm{animal} / \mathrm{dia})$, relacionada à pequena quantidade de forragem verde e lâmina foliar disponível.

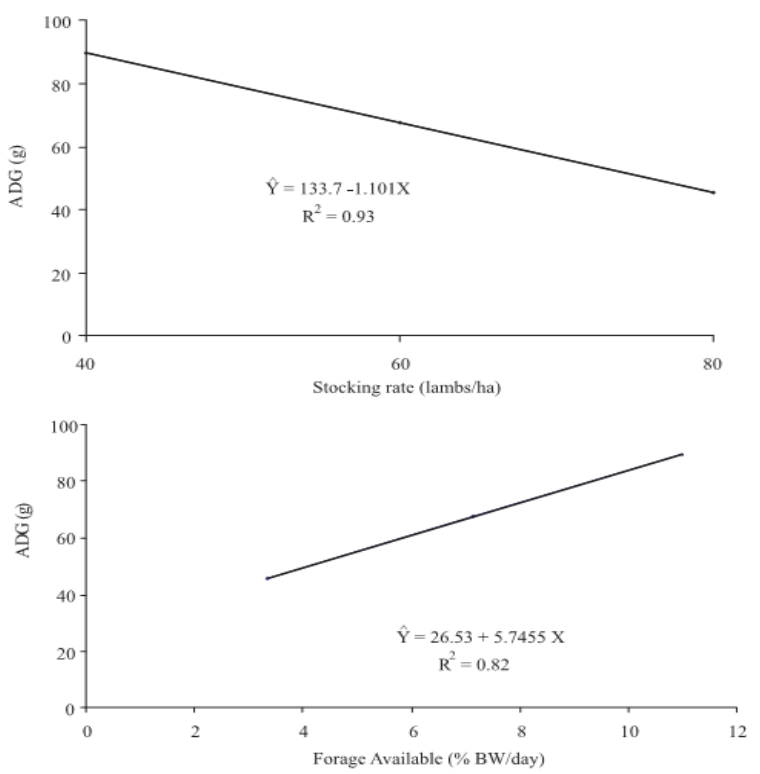

Figura 18. Ganho médio diário (GMD) de cordeiros estimado em função da taxa de lotação e forragem disponível. Fonte: Vieira Júnior et al. (2011).

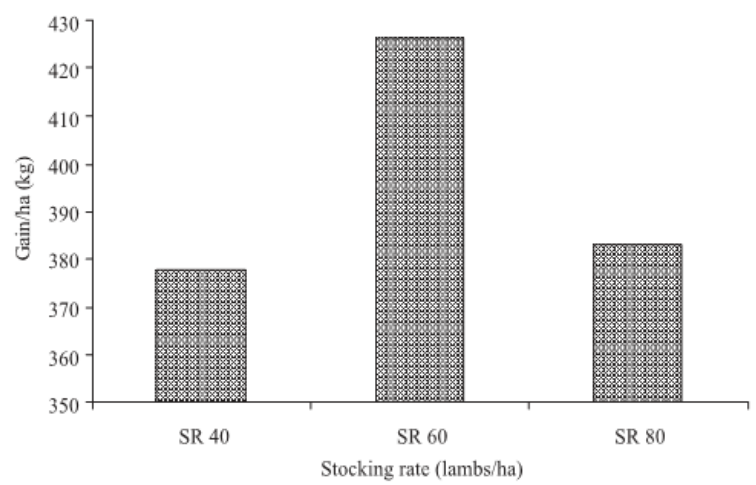

Figura 19. Média do ganho de peso por área em função da taxa de lotação. Fonte: Vieira Júnior et al. (2011). 
Em estudo com 22 bovinos Nelore não castrados, Machado et al. (2012) avaliaram o efeito dos níveis de suplementação sobre o desempenho, as características de carcaça, a composição corporal e as exigências de energia e proteína de bovinos de corte sob pastejo. Foram avaliados quatro tratamentos: controle ou mistura mineral (MM), $1 \mathrm{~kg}, 2 \mathrm{~kg}$ e $3 \mathrm{~kg}$ de suplemento ao dia (Tabela 12), com quatro repetições, durante um período de 84 dias.

As exigências líquidas de energia para mantença (ELm) foram estimadas a partir da relação exponencial entre a produção de calor (PC, Mcal/kg PCVZ0,75) e o consumo de energia metabolizável (CEM, Mcal $/ \mathrm{kg} \mathrm{PCVZ}^{0,75}$ ) (Figura 20), conforme preconizado por (Ferrell \& Jenkins 1998b, a).

Tabela 12. Composição porcentual dos suplementos, com base na matéria natural.

\begin{tabular}{lcccc}
\hline \multirow{2}{*}{ Ingredientes (\%) } & \multicolumn{4}{c}{ Tratamentos (suplemento, $\mathrm{PC}^{1}$ ) } \\
\cline { 2 - 5 } & $\mathrm{MM}^{3}$ & 0,33 & 0,66 & 1,00 \\
\hline Mistura mineral $^{2}$ & 100 & 6,0 & 3,0 & 2,0 \\
Ureia/SA - 9:1 & --- & 4,8 & 4,8 & 4,8 \\
$\begin{array}{l}\text { Farelo de algodão } \\
\text { 38\% PB }\end{array}$ & --- & 30,0 & 30,0 & 30,0 \\
$\begin{array}{l}\text { Grão de milho } \\
\text { triturado }\end{array}$ & --- & 59,2 & 62,2 & 63,2 \\
\end{tabular}

${ }^{1}$ Peso corporal; ${ }^{2}$ Fosfato bicálcico, $50 \%$; Cloreto de sódio, 47,8\%; Sulfato de zinco, 1,4\%; Sulfato de cobre, 0,70 ; Sulfato de cobalto, $0,05 \%$; e Iodato de potássio, $0,05 \%$.

${ }^{3}$ Mistura mineral. Fonte: Machado et al. (2012).

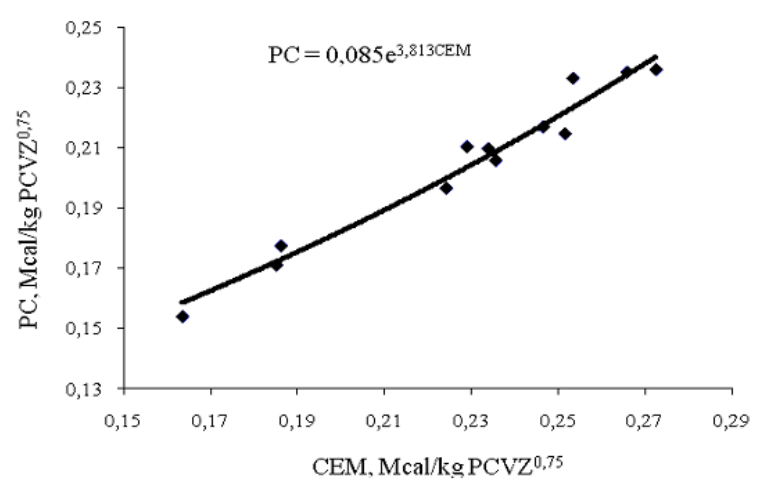

Figura 20. Razão entre produção de calor (PC) e consumo de energia metabolizável (CEM) em bovinos sob pastejo. Fonte: Machado et al. (2012).

De acordo com Machado et al. (2012), a equação foi traçada com os dados de todos os animais do experimento, sendo a estimativa da $\mathrm{ELm}$ de $85 \mathrm{kcal} / \mathrm{kg} \mathrm{PCVZ}^{0,75}$. Este valor foi superior àqueles relacionados por Valadares Filho et al. (2016), de 69,33 e $74,01 \mathrm{kcal} / \mathrm{kg}$ $\mathrm{PCVZ}^{0,75}$, respectivamente, os quais trabalharam com animais em condições semelhantes às deste estudo.
Conforme salientado anteriormente, animais em pastejo podem apresentar requisitos de energia para mantença maior do que aqueles criados em confinamento, em razão da maior atividade física que exercem. Osuji (1974) observou que a atividade de pastejo pode aumentar os requerimentos de energia de ruminantes de 25 a $50 \%$ em comparação aos animais em confinamento e que considerável parte deste aumento pode ser atribuído ao gasto energético para locomoção e colheita de forragem.

O requisito de energia metabolizável para mantença tem sido definido como sendo o consumo de energia metabolizável (CEM) por dia, em que o balanço energético do animal torna-se nulo (Dawson \& Steen 1998). A equação obtida por Machado et al. (2012) foi: $E R=0,246$ x CEM - 0,032 (Figura 21). De acordo com essa equação, as exigências de energia metabolizável para mantença de bovinos Nelore a pasto seriam de $130,08 \mathrm{kcal} / \mathrm{kg} \mathrm{PCVZ}{ }^{0,75}$, com uma eficiência de utilização da energia metabolizável para ganho $(\mathrm{kg})$ de 24,6\%. Dividindo-se as exigências de $\operatorname{ELm}(85,0)$ pelas exigências de $\operatorname{EMm}(130,1)$, obteve-se o valor da eficiência de uso da energia metabolizável para mantença $(\mathrm{km})$ de $64,2 \%$.

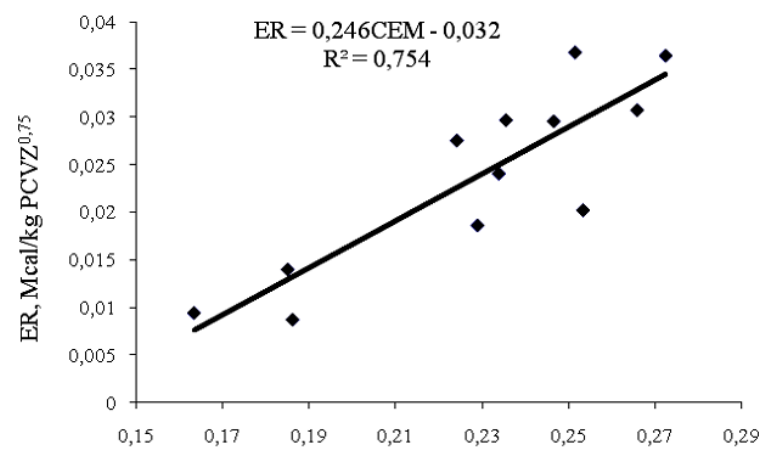

Figura 21. Relação entre energia retida (ER) e consumo de energia metabolizável em bovinos a pasto. Fonte: Machado et al. (2012).

\section{Considerações finais}

O conhecimento do gasto energético de bovinos em regime de pastejo é de extrema importância para o atendimento as exigências nutricionais de bovinos, já que a alimentação tem grande impacto sobre os custos de produção. Nessa ótica, estudos mais específicos para a região de clima tropical ainda precisam ser conduzidos para que as lacunas possam ser preenchidas e a determinação do gasto energético dos animais possam apresentar uma maior acurácia. 


\section{Referências bibliográficas}

Baggio C., Carvalho P.C.F., Silva J.L.S., Rocha L.M., Bremm C., Santos D.T. \& Monteiro A.L.G. (2008) Padrões de uso do tempo por novilhos em pastagem consorciada de azevém anual e aveia-preta. Revista Brasileira de Zootecnia 37, 1912-8.

Bailey D.W., Gross J.E., Laca E.A., Rittenhouse L.R., Coughenour M.B., Swift D.M. \& Sims P.L. (1996) Mechanisms that result in large herbivore grazing distribution patterns. Journal of Range Management 49, 386-400.

Berchielli T.T., Pires A.V. \& Oliveira S.G. (2011) Nutrição de Ruminantes. FUNEP, Jaboticabal, Brazil.

Brosh A., Henkin Z., Ungar E.D., Dolev A., Orlov A., Yehuda Y. \& Aharoni Y. (2006) Energy cost of cows' grazing activity: Use of the heart rate method and the Global Positioning System for direct field estimation1. Journal of animal science 84, 1951-67.

Brosh A., Henkin Z., Ungar E.D., Dolev A., Shabtay A., Orlov A., Yehuda Y. \& Aharoni Y. (2010) Energy cost of activities and locomotion of grazing cows: A repeated study in larger plots 1. Journal of animal science 88, $315-23$

Cabral L.S., Valadares Filho S.d.C., Detmann E., Malafaia P.A.M., Zervoudakis J.T., Souza A.L., Veloso R.G. \& Nunes P.M.M. (2006) Consumo e digestibilidade dos nutrientes em bovinos alimentados com dietas à base de volumosos tropicais. Revista Brasileira de Zootecnia 35, 2406-12.

Carvalho G.G.P., Pires A.J.V. \& Silva F.F. (2004) Comportamento ingestivo de cabras leiteiras alimentadas com farelo de cacau ou torta de dendê. Revista Brasileira de Zootecnia 39, 919-25.

Carvalho G.G.P., Pires A.J.V., Silva R.R., Ribeiro L.S.O. \& Chagas D.M.T. (2008) Comportamento ingestivo de ovinos Santa Inês alimentados com dietas contendo farelo de cacau. Revista Brasileira de Zootecnia 37, 660-5.

Charnov E.L. (1976) Optimal foraging, the marginal value theorem. Theoretical population biology 9, 129-36.

Dawson L.E.R. \& Steen R.W.J. (1998) Estimation of maintenance energy requirements of beef cattle and sheep. The Journal of Agricultural Science 131, 477-85.

Ferraz J.B.S. \& Felício P.E. (2010) Production systems - An example from Brazil. Meat Science 84, 238-43.

Ferrell C.L. \& Jenkins T.G. (1998a) Body composition and energy utilization by steers of diverse genotypes fed a high-concentrate diet during the finishing period: I. Angus, Belgian Blue, Hereford, and Piedmontese sires. Journal of animal science 76, 637-46.

Ferrell C.L. \& Jenkins T.G. (1998b) Body composition and energy utilization by steers of diverse genotypes fed a high-concentrate diet during the finishing period: II. Angus, Boran, Brahman, Hereford, and Tuli sires. Journal of animal science 76, 647-57.

Freitas J.A., Queiroz A.C., Dutra A.R., Vieira R.A.M., Lana R.P., Leonel F.d.P., Henrique D.S., Lima A.V. \& Souza J.C. (2006) Composição do ganho e exigências de energia e proteína para ganho de peso em bovinos Nelore puros e mestiços. Revista Brasileira de Zootecnia 35.

Hodgson J. (1990) Grazing management. Science into practice. Longman Group UK Ltd., London.

Laca E.A., Ungar E.D., Seligman N. \& Demment M.W. (1992) Effects of sward height and bulk density on bite dimensions of cattle grazing homogeneous swards. Grass and forage science 47, 91-102.

Lachica M., Barroso F.G. \& Prieto C. (1997) Seasonal variation of locomotion and energy expenditure in goats under range grazing conditions. Journal of Range Management 50, 234-8.

Lawrence T.L.J., Fowler V.R. \& Novakofski J.E. (2012) Growth of farm animals. CABI, USA.

Machado P.A.S., Valadares Filho S.C., Valadares R.F.D., Paulino M.F., Paulino P.V.R. \& Marcondes M.I. (2012) Desempenho e exigências de energia e proteína de bovinos de corte em pasto suplementados. Arquivo Brasileiro de Medicina Veterinária $e$ Zootecnia 64, 683-92.

Marcondes M.I., Chizzotti M.L., Valadares Filho S.C., Gionbelli M.P., Paulino P.V.R. \& Paulino M.F. (2010) Exigências nutricionais de energia para bovinos de corte. In: Exigências nutricionais de zebuínos puros $e$ cruzados BR-CORTE (eds. by Valadares Filho 
SC, Marcondes MI, Chizzotti ML \& Paulino PVR), pp. 85-111. Universidade Federal de Viçosa.

Moraes E.H.B.K., Paulino M.F., Andreatta K., Moraes K., Figueiredo D.M., Valadares Filho S.C., Paulino P.V.R. \& Couto V.R.M. (2009) Exigências de energia de bovinos de corte em pastejo. Revista Brasileira de Zootecnia 38, 933-40.

NRC (2000) Nutrient Requirements of Beef Cattle. Natl. Acad. Press, Washington, DC, USA.

Osuji P.O. (1974) The physiology of eating and the energy expenditure of the ruminant at pasture. Journal of Range Management 27, 437-43.

Palhano A.L., Carvalho P.C.F., Dittrich J.R., Moraes A., Silva S.C. \& Monteiro A.L.G. (2006) Padrões de deslocamento e procura por forragem de novilhas leiteiras em pastagem de capim-mombaça. Revista Brasileira de Zootecnia 35, 2253-9.

Prache S. (2009) Diet authentication in sheep from the composition of animal tissues and products. Revista Brasileira de Zootecnia 38, 362-70.

Prache S., Gordon I.J. \& Rook A.J. (1998) Foraging behaviour and diet selection in domestic herbivores. Animal Research 47, 335-45.

Prache S., Kondjoyan N., Delfosse O., Chauveau-Duriot B., Andueza D. \& Cornu A. (2009) Discrimination of pasture-fed lambs from lambs fed dehydrated alfalfa indoors using different compounds measured in the fat, meat and plasma. animal 3, 598-605.

Prado I.N. (2010) Produção de bovinos de corte e qualidade da carne. Eduem, Maringá, Paraná, Brasil.
Sahlu T., Jung H.G. \& Morris J.G. (1989) Influence of grazing pressure on energy cost of grazing by sheep on smooth Bromegrass. Journal of animal science 67, 2098-105.

Sarmento J.L.R., Pimenta Filho E., Ribeiro M.N. \& Martins Filho R. (2003) Efeitos ambientais e genéticos sobre o ganho em peso diário de bovinos Nelore no estado da Paraíba. Revista Brasileira de Zootecnia 32, 325-30.

Teixeira F.A., Bonomo P., Pires A.J.V., Silva F.F., Marques J.A. \& Santana Júnior H.A.S. (2011) Padrões de deslocamento e permanência de bovinos em pastos de Brachiaria decumbens diferidos sob quatro estratégias de adubação. Revista Brasileira de Zootecnia 40, 1489-96.

Valadares Filho S.C., Costa e Silva L.F., Gionbelli M.P., Rotta P.P., Marcondes M.I., Chizzotti M.L. \& Prados L.F. (2016) Exigências nutricionais de zebuínos puros $e$ cruzado - BR-Corte. Universidade Federal de Viçosa, Viçosa, Minas Gerais.

Vieira Júnior L.C., Silva C.L., Zervoudakis J.T., Abreu J.G., Souza A.L. \& Morenz M.J.F. (2011) Ingestive behavior and performance of female lambs grazing on Marandu palisadegrass under different stocking rates 1. Revista Brasileira de Zootecnia 40, 2359-63.

Article History:

Received 13 February 2018

Accepted 13 March 2018

Available online 15 May 2018

License information: This is an open-access article distributed under the terms of the Creative Commons Attribution License 4.0, which permits unrestricted use, distribution, and reproduction in any medium, provided the original work is properly cited. 